responses to live E. coli and endotoxin shock in the monkey. J Appl Physiol 26:780

16. Harrison LH, Hinshaw LB, Coalson JJ, Greenfield LJ 1971 Effects of E. coli septic shock on pulmonary hemodynamics and capillary permeability. J Thorac Cardiovasc Surg 61:795

17. Hess ML, Komwatana P, Krause S, Bruni FD 1979 Augmented venous return: protection of ischemic myocardium during endotoxinemia. Adv Shock Res 2:257

18. Hieber P, Nelson A, McCracken GH 1977 Acute disseminated staphlococcal disease in childhood. Am J Dis Child 131:181

19. Hinshaw LB, Mathis MC, Nanaeto JA, Holmes DD 1970 Recovery patterns and lethal manifestations of live E. coli organism shock. J Trauma 10:787

20. Hinshaw LB, Solomon LA, Holmes DD, Greenfield LJ 1968 Comparison of canine responses to Escherichia coli organisms and endotoxin. Surg Gynecol Obstet 11:981

21. Katzenstein AL, Davis C, Braude A 1976 Pulmonary changes in neonatal sepsis due to group B beta-hemolytic streptococcus: relation to hyaline membrane disease. J Infect Dis 133:430

22. Korones SF, Fabien GA 1975 Successful treatment of 'persistent fetal circulation.' Pediatr Res 9:367

23. Krausz MM, Perel A, Eimerl D, Cotev S 1977 Cardiopulmonary effects of volume loading in patients in septic shock. Ann Surg 185:429

24. Lee EL, Robinson MJ, Thong ML, Puthucheary SD, Ong TH, Ng KK 1977 Intraventricular chemotherapy in neonatal meningitis. J Pediatr 91:991

25. Lock J 1979 Direct and indirect pulmonary vascular effects of tolazoline in the newborn lamb. J Pediatr 95:600

26. Meadow WL, Meus PJ 1980 An animal model of neonatal sepsis: cardiovascular sequelae of type $1 \mathrm{~b}$ group B beta strep bacteremia in the newborn piglet. Pediatr Res 14:606 (abst)

27. Menke JA, Giacoia GP, Jockin H 1979 Group B beta hemolytic streptococcal sepsis and the idiopathic respiratory distress syndrome: a comparison. J Pediatr 94:467

28. Perkin RM, Levin DL 1982 Shock in the pediatric patient: therapy. J Pediatr 101:319

29. Quirante J, Ceballos R, Cassady G 1974 Group B beta-hemolytic streptococcal infection in the newborn. Am J Dis Child 128:659

30. Riemenschneider TA, Brenner RA, Mason DT 1981 Maturational changes in myocardial contractile state of newborn lambs. Pediatr Res 15:349

31. Rojas J, Green RS, Hellerqvist CG, Olegard R, Brigham KL, Stahlman MT 1981 Studies on group B beta-hemolytic streptococcus. II. Effects on pulmonary hemodynamics and vascular permeability in unanesthetized sheep. Pediatr Res 15:899

32. Rommero TE, Friedman WF 1979 Limited left ventricular response to volume overload in the neonatal period: a comparative study with the adult animal. Pediatr Res 13:910

33. Sembrat RF, DiStazio J, Stremple JF 1979 The pony as a model for septic shock. Adv Shock Res 2:137

34. Siegel JD, McCracken GH 1981 Sepsis neonatorum. N Engl J Med 304:642

35. Stevenson DK, Kasting DS, Darnall RA, Ariagno RL, Johnson JD, Malachowski N, Beets CL, Sunshine P 1979 Refractory hypoxemia associated with neonatal pulmonary disease: The use and limitations of tolazoline. J Pediatr 95:595

36. Tripp ME, Drummond WH, Heymann MA, Rudolph AM 1980 Hemodynamic effects of pulmonary arterial infusion of vasodilators in newborn lambs. Pediatr Res 14:1311

37. Wright CJ, Duff JH, McLean AP, MacLean LD 1971 Regional capillary blood flow and oxygen uptake in severe sepsis. Surg Gynecol Obstet 64:637

38. Young LS 1977 Gram-negative rod bacteremia: microbiologic, immunologic, and therapeutic considerations. Ann Intern Med 86:456

\title{
Experimental Neonatal Syphilis. I. Evidence of Resistance to Symptomatic Infection in Neonatal Rabbits following Intradermal Inoculation with Treponema pallidum (Nichols Strain)
}

\author{
DARLENE GAMBOA AND JAMES N. MILLER \\ Treponemal Research Laboratory, Department of Microbiology and Immunology, University of California at Los \\ Angeles, Los Angeles, California 90024
}

\section{Summary}

Resistance of 5- to 8-day-old neonatal rabbits to dermal lesion development after intradermal inoculation of Treponema pallidum was demonstrated. Clinical evidence of infection following inoculation of $1 \times 10^{6}$ Treponema pallidum at each of two sites was either minimal or absent. Atypical, nonprogressive, nonulcerative lesions occurred in $59 \%$ of the inoculated neonates and at $45 \%$ of inoculated sites. Differences in incubation periods, duration, and maximum diameters of lesions among adult controls versus neonatal rabbits were significant. The age of waning resistance was determined by inoculating groups of neonates

Received August 1, 1983; accepted March 12, 1984.

Address reprint requests to Dr. Darlene Gamboo, Department of Biology, California State University at San Bernadino, San Bernadino, CA. 92407.

This study was supported by United States Public Health Service Grant AI12601 from the National Institutes of Health and by World Health Organization Agreement V3/181/26 and represents partial fulfillment of the requirements for the Doctor of Philosophy degree at UCLA by D. G. ranging from 1 to 7 weeks of age. Five-week-old (31-36 days) neonates demonstrated waning resistance by the appearance of typically ulcerative, progressive lesions, though their parameters (duration, size) were not yet those of adult control lesions. The resistance demonstrated by neonates may be due in part to group housing (nesting) which could create unfavorable temperatures for $\boldsymbol{T}$. pallidum survival; comparison of lesion development between nesting and individually housed neonates, 31 to 46 days of age, revealed a greater percentage of typical lesions developing among those individually housed ( 95 versus $52 \%$ ). However, these differences may reflect the variability of typical lesion development found among animals of this age when resistance begins to wane. In both groups, the duration of typical lesions was significantly shorter than for adult controls. A heat-stable serum factor(s) was demonstrated in 19 of 20 basal sera from neonates 4 to 6 days of age; this presented another possible mechanism of resistance. The neutralizing serum factor(s) was not demonstrable in the sera of does either before mating, during gestation, or shortly after kindling. The relationship of temperature, serum 
factors, and nutritional factors to neonatal resistance following intradermal inoculation with $T$. pallidum is discussed.

\section{Abbreviations}

\author{
VDRL, Venereal Disease Research Laboratory \\ NRS, nonimmune rabbit serum \\ IRS, immune rabbit serum \\ Micro-NZ, microneutralization
}

The advent of penicillin therapy brought about a dramatic reduction in the incidence of congenital syphilis $(12,34,39)$. However, the decline in both the use of routine screening procedures and physicians' training programs has resulted in the reemergence of this form of the disease as a public health problem $(2,11,34,38,46,49,50,60)$. Despite this problem, little is known about the interacting events associated with the organism and host which determine infectivity. Since the recognition of congenital syphilis as a distinct clinical entity, it has been generally accepted that treponemes cross the placenta only after the 4th month of gestation, at a time when the Langhans cell layer (cytotrophoblast) becomes atrophied (20). Recent evidence, however, indicates that treponemes can be found in conceptus material obtained during the first trimester (21). Silverstein and Lukes (43) and Silverstein (42) have suggested that infection during early gestation may go undetected due to the absence of an inflammatory reaction attributed to the immaturity of the fetal immune system. The introduction of Treponema pallidum from an infected mother to fetus may result in either a fulminating fatal disease, latency, or the absence of infection; factors which influence the outcome are not understood. The lack of a satisfactory and reproducible experimental rabbit model has precluded studies on the pathogenesis and immunology of both the congenital and neonatal disease. Conflicting results have been reported by investigators who have attempted to demonstrate transmission of the disease from infected pregnant does to their offspring $(4,16,19,26,27,33,40,53)$. Data comparison of these studies is hampered by differences in experimental design, including the time, route, and dose of inoculations of $T$. pallidum suspensions. Those investigators who have argued the existence of innate fetal resistance to $T$. pallidum infection disagree as to the time of occurrence and the degree of susceptibility after birth $(16,26,33)$. Festenstein and Bokkenheuser (16) and Festenstein et al. (15) reported a runting syndrome in neonates inoculated through 2 weeks of age. In contrast, Pautrizel et al. (33), Kemp and Fitzgerald (26), and Kemp and Rosahn (27) have reported the absence of infection or presence of asymptomatic infection in several animals. Again, the variable experimental designs preclude accurate data comparison.

The conflicting and confusing picture which has emerged as a result of these investigations prompted the initiation of studies to determine the susceptibility versus resistance of neonatal rabbits to infection with $T$. pallidum. This report provides the first definitive evidence of neonatal resistance to symptomatic infection, which begins to subside as the animal reaches 5 weeks of age. The potential influences of nesting and serum neutralizing factors upon resistance are advanced.

\section{MATERIALS AND METHODS}

Rabbits. Adult ( $\geq 6$-month-old) New Zealand albino rabbits with nonreactive VDRL serologic tests were used throughout this study. Neonates were offspring of VDRL nonreactive animals mated in this laboratory. They were housed with their doe, unless otherwise specified, until they reached approximately 6 to 8 weeks of age, at which time they were weaned. For the purpose of this study, "neonate" will refer to any offspring. Blood for serological studies was obtained by cardiac puncture (27 gauge, $5 / 8$-inch needle) from newborns prior to inoculation with $T$. pallidum; they were then placed under a warm lamp to prevent shock. Growth and development were monitored by periodic assessment of weight gain and physical appearance. Experimental groups of neonates were formed by sampling animals from more than one litter when possible. All rabbits were housed at 18$21^{\circ} \mathrm{C}$ and given antibiotic-free food and water ad libitum.

Mating. For mating, a doe was placed in a cage containing a single buck for 1 to $2 \mathrm{~h}$ on 2 successive days. A different buck was used each day. Three to 7 days prior to kindling, the doe was transferred to a special breeding cage containing a nesting box. Gestation was counted from the first mating day and observed to be an average of $31.5 \pm 1.2$ days (range, 29 to 35 days).

Source of T. pallidum. T. pallidum, Nichols strain, was maintained by intratesticular passage in rabbits. Normal animals were infected by inoculation of $1.0 \mathrm{ml} /$ testis of a suspension containing $2 \times 10^{7}$ treponemes $/ \mathrm{ml}$. At the height of orchitis development, usually 8 to 11 days, the animal was sacrificed by intracardiac injection of a lethal amount of Euthanol-6 (Trico-Pharmaceutical Company, San Carlos, CA) and the testes were removed aseptically.

The testes were sliced longitudinally and the treponemes were harvested in an appropriate medium (described separately for each experimental procedure below). The suspension was centrifuged at $250 \times \mathrm{g}$ for $7 \mathrm{~min}$ to remove gross cellular debris. Treponemal concentration was determined by dark field microscopy (31) and was adjusted appropriately for each assay with the respective extraction medium.

Inoculation of neonates. The treponemal suspension for inoculation of neonates was prepared as described above using an extraction medium of $50 \%$ heated $\left(56^{\circ} \mathrm{C}, 30 \mathrm{~min}\right) \mathrm{NRS}$ and $50 \%$ phosphate-buffered saline. The final suspension was adjusted with the serum-saline medium to contain $2 \times 10^{7}$ treponemes/ $\mathrm{ml}$. Neonatal rabbits were inoculated intradermally on their clipped backs at two sites with $0.05 \mathrm{cc}$ of the suspension $\left(1 \times 10^{6}\right.$ treponemes/site). As controls, adult animals were similarly inoculated at two to four sites. All animals were regularly clipped and monitored for lesion development; aspirates of representative lesions were examined by dark field microscopy for the presence of motile treponemes.

Table 1. Lesion development in 5- to 8-day-old neonatal rabbits inoculated intradermally with I. pallidum*

\begin{tabular}{|c|c|c|c|c|c|c|c|c|c|c|}
\hline \multirow[b]{2}{*}{ Animals } & \multirow[b]{2}{*}{ Age } & \multirow{2}{*}{$\begin{array}{c}\text { Animals } \\
\text { with } \\
\text { lesions/total }\end{array}$} & \multirow[b]{2}{*}{ Percentage } & \multirow[b]{2}{*}{$\begin{array}{l}\text { Lesions/ } \\
\text { sites }\end{array}$} & \multirow[b]{2}{*}{ Percentage } & \multicolumn{2}{|c|}{$\begin{array}{l}\text { Incubation period } \\
\text { (days) }\end{array}$} & \multirow[b]{2}{*}{$\begin{array}{l}\text { Mean duration } \\
\text { (days) }\end{array}$} & \multirow{2}{*}{$\begin{array}{c}\text { Mean } \\
\text { maximum } \\
\text { diameter } \\
(\mathrm{mm})\end{array}$} & \multirow[b]{2}{*}{$\begin{array}{c}\text { Lesion } \\
\text { appearance } \dagger\end{array}$} \\
\hline & & & & & & Mean & Range & & & \\
\hline Adults & $\geq 6 \mathrm{mo}$ & $31: 31$ & 100 & $100: 100$ & 100 & $3.35 \pm 0.74 \S$ & $2-6$ & $29.89 \pm 9.29^{* *}$ & $16.30 \pm 3.00 \pi$ & Typical \\
\hline
\end{tabular}

* Inoculated with $1 \times 10^{6}$ treponemes/site; 2 sites/neonate and 2-4 sites/adult. Values are mean \pm SD.

$\dagger$ Atypical, indurated, small, nonprogressive, nonulcerative lesions; typical, erythematous, indurated, enlarged lesions that progress to ulceration. $\ddagger p<0.05$, Mann-Whitney $\mathrm{U}$ test.

$\S$ Cumulative data from seven experiments.

I Cumulative data from four of seven experiments; three experiments terminated before determination of duration.

** Cumulative data from two of seven experiments; five experiments terminated before determination of maximum diameter. 
Neutralization assays. A neutralization assay on pooled neonatal sera was performed by the method of Bishop and Miller (5). Briefly, T. pallidum were collected in heated $\left(56^{\circ} \mathrm{C}, 30 \mathrm{~min}\right)$ NRS from the testes of 9-day infected rabbits and adjusted with the same medium to $10^{5} \mathrm{~T}$. pallidum $/ \mathrm{ml}$. The test suspension was prepared with $0.1 \mathrm{ml}$ of the treponeme suspension and 0.9 $\mathrm{ml}$ of undiluted pooled neonatal sera for a final concentration of $10^{4} \mathrm{~T}$. pallidum $/ \mathrm{ml}$. The limited volume of serum obtainable from individual animals necessitated the development of a microtest modification of the neutralization assay for use in testing individual neonatal sera. In the micro-NZ, the test suspension was prepared with $90 \mu \mathrm{l}$ of undiluted test serum and $10 \mu \mathrm{l}$ of a T. pallidum suspension prepared with undiluted, heated NRS $\left(56^{\circ} \mathrm{C}, 30 \mathrm{~min}\right)$ and contained $1 \times 10^{4}$ treponemes in a volume of $0.1 \mathrm{ml}$. The test suspensions were equilibrated with $95 \% \mathrm{~N}_{2}$, $5 \% \mathrm{CO}_{2}$ and incubated for $16 \mathrm{~h}$ at $34^{\circ} \mathrm{C}$. After incubation, the test mixtures were adjusted to a working volume of $1.0 \mathrm{ml}$ containing $1 \times 10^{4}$ treponemes by diluting with NRS extraction medium. The viability of the treponemes in each test mixture was assessed by intradermal inoculation of adult rabbits on their clipped backs as previously described (25); 0.1 -ml volumes of the diluted test mixture were injected so that each site received $1 \times 10^{3}$ treponemes. The absence of lesion development after a 31-45-day observation period was considered evidence for complete neutralization. The development of lesions after a significant delay in incubation compared to adult controls was considered evidence for partial neutralization.

Control nonimmune rabbit sera were obtained from noninfected, VDRL nonreactive adult rabbits susceptible to symptomatic infection with T. pallidum. Control IRS was obtained from infected adult rabbits immune to symptomatic reinfection as defined by the absence of lesions upon intradermal challenge with $1 \times 10^{6} T$. pallidum/site. Sera from adult control animals were obtained 1 to 6 months prior to use and stored together with the sera of neonates at $-76^{\circ} \mathrm{C}$.

Statistical analysis. The incubation periods, duration, and maximum diameters of lesions in neonates were compared with lesions in adult control animals by the Mann-Whitney U test or Student's $t$ test, depending on population assumption. The differences in the results were considered to be significant if $p<$ 0.05 .

\section{RESULTS}

Lesion development in neonatal rabbits following intradermal inoculation with T. pallidum. Neonatal rabbits 5 to 8 days of age showed marked resistance to the development of dermal lesions following intradermal inoculation with $1 \times 10^{6} T$. pallidum (Table 1). In the cumulative data from seven separate experiments, only 39 of $66(59 \%)$ inoculated neonates and 60 of 132 (45\%) inoculated sites developed lesions. In each instance, the lesions were nonulcerative, nonprogressive, and of short duration (atypical). This was in marked contrast to the adult control animals in which typically progressive and ulcerative lesions occurred at all 100 inoculated sites. Further evidence for neonatal resistance was provided by the significant delay in the incubation periods of the neonatal lesions ( $7.53 \pm 3.42$ days) as compared to the adult controls ( $3.35 \pm 0.74$ days). In addition, the duration of lesions which developed among neonatal animals was markedly shorter $(4.03 \pm 2.82$ days $)$ than lesions of adult controls $(29.89 \pm 9.29$ days). The duration of lesions in adult control animals was determined in only two of the seven experiments; however, this value has been corroborated by repeated determinations in this laboratory in which a mean duration value of $32.2 \pm 6.2$ days for 111 lesions has been obtained (personal communication, N. H. Bishop). The mean of $5.82 \pm 1.81 \mathrm{~mm}$ was significantly smaller than control lesions which reached a maximum diameter of $16.2 \pm 3.0 \mathrm{~mm}$. Dark field examination of material aspirated from representative adult lesions revealed actively motile treponemes. In contrast, aspirates of representa-

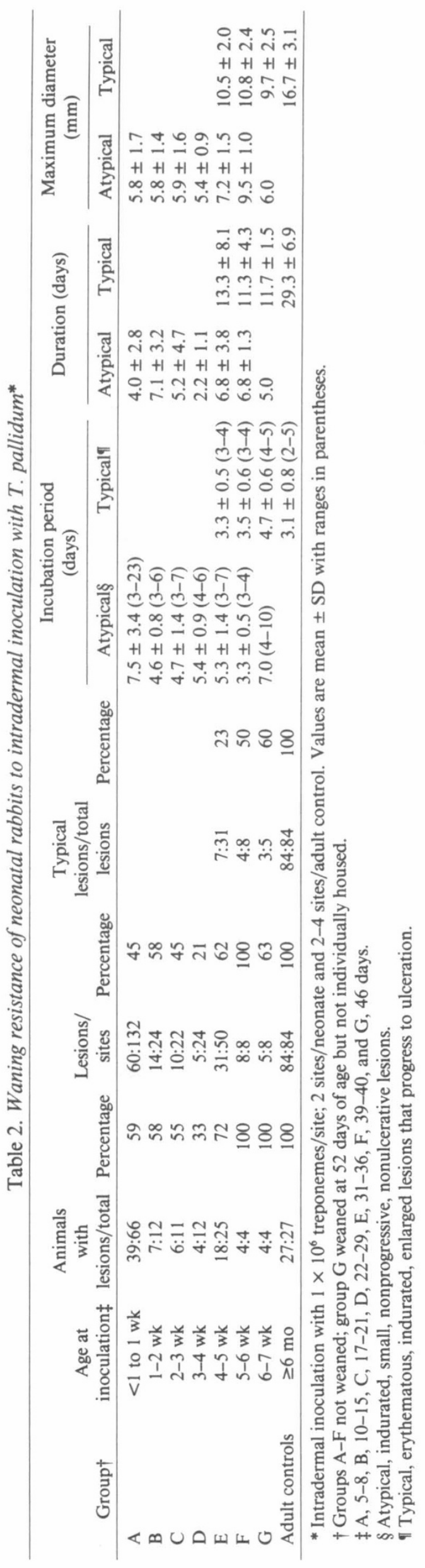


tive neonate lesions were most often negative; treponemes, when observed, were either sluggish or nonmotile.

The data clearly indicate the difference in character between neonate and adult lesions. The atypical appearance of the former as indurated, small, nonprogressive, nonulcerative lesions together with delayed incubation periods was indicative of resistance to clinical evidence of infection with $T$. pallidum. The general health and development of neonates inoculated at 5 to 8 days of age was the same as that of normal uninoculated littermates; no evidence of runting was observed.

Age of waning resistance. In an attempt to determine the age at which resistance of intradermal infection with $T$. pallidum begins to wane among neonatal rabbits, groups of animals ranging in age from approximately 1 to 7 weeks ( 5 to 46 days) were inoculated at 2 sites with $1 \times 10^{6}$ treponemes/site. As shown in Table 2, typical lesions began to appear consistently in animals inoculated at approximately 5 weeks of age. The lesions were progressive in that they enlarged and ulcerated. Further evidence for waning resistance was provided by the comparable incubation periods of typical lesions among neonates and adult controls. There was a definite pattern for typical lesions of neonates to become larger and persist longer than their atypical counterparts; however, through 7 weeks of age, they had not yet achieved the dimensions or durations of adult control lesions. It is of interest to note that the outcome following inoculation of neonates was independent of litter source; the degree of resistance was an individual event varying from neonate to neonate.

Influence of nesting on neonatal resistance. Experimental syphilis in rabbits requires that the animals be kept in cool quarters $\left(18-21^{\circ} \mathrm{C}\right)$ to facilitate proper lesion development following intradermal inoculation with $T$. pallidum (25). Thus, it is conceivable that higher temperatures due to huddling of neonates in a nest (nesting) may contribute to their resistance. Attempts to wean neonates at 1 week of age were unsuccessful and prevented the testing of our huddling hypothesis at this age. The essentially complete transition from doe's milk to rabbit food pellets at 4 weeks of age permitted the determination of nesting effects on lesion development in older neonates. Table 3 summarizes the results of three experiments in which inoculated neonates ranging in ages of approximately $4 \frac{1}{2} 2$ to $6 \frac{1}{2}$ weeks (31-46 days) were either housed individually or allowed to nest. Lesions developed at each of the 20 inoculated sites among the individually housed animals and at 21 of 24 sites among nesting neonates so that all animals had developed at least one lesion. However, $95 \%$ of the lesions which developed among the individually housed animals were typical, as compared to $52 \%$ among the nesting animals; the remaining lesions were atypical. The incubation periods of the typical lesions in both groups were essentially the same and compatible with individually housed adult controls. No significant differences were observed between the two groups of neonates with respect to either duration or maximum diameter of lesions. Thus, the major difference between individually housed and nesting neonates was the number of typical lesions that occurred within each group. This difference may simply reflect the variability in typical lesion development observed among animals at the age of waning resistance (Table 2) rather than an effect due to nesting.

Neutralization of T. pallidum by serum from 4- to 6-day-old noninfected neonates. Standard neutralization assays performed on pooled neonatal basal sera revealed inactivation of virulent T. pallidum. This presented the possibility that the neutralization of $T$. pallidum may be another mechanism of resistance. Table 4 summarizes the results of five experiments in which the presence of neutralizing activity was determined on individual sera from 4- to 6-day-old neonates prior to their subsequent intradermal inoculation at 5 to 8 days of age.

Analysis of the total number of neutralization inoculation sites as shown in Table 4 demonstrated the presence of neutralizing activity in neonatal basal serum samples. Analysis of individual neonatal serum samples showed that 15 sera possessed complete neutralization activity, four sera demonstrated partial neutralization ( 1 or 3 of 5 inoculation sites/sample developed lesions after delayed incubation periods), and one serum failed to neutralize.

Table 4. Neutralization of T. pallidum by serum from 4- to 6day-old noninfected neonates resistant to subsequent infection*

\begin{tabular}{ccc}
\hline \multirow{2}{*}{$\begin{array}{c}\text { Status of resistance } \\
\text { to symptomatic infection }\end{array}$} & \multicolumn{2}{c}{ Serum neutralization $\dagger$} \\
\cline { 2 - 3 } & Unheated serum & Heated serum $\ddagger$ \\
\hline $\begin{array}{c}\text { Neonates } \\
\text { Resistant }\end{array}$ & $10: 99(20)$ & $9: 99(20)$ \\
Adult controls & & \\
$\quad$ Resistant & $1: 54^{* *}(5)$ & $47: 54^{* *}(5)$ \\
Susceptible & $54: 54(5)$ & $53: 54(5)$ \\
\hline
\end{tabular}

* Summary of five micro-NZ experiments. See "Materials and Methods."

$\dagger$ Minimum of four inoculation sites/serum sample. Values show number of lesions per sites inoculated, with number of serum samples in parentheses.

$\ddagger 56^{\circ} \mathrm{C}, 30 \mathrm{~min}$.

$\S$ Neonates were inoculated intradermally with $1 \times 10^{6} \mathrm{~T}$. pallidum at each of two sites, 1-4 days postbleeding for basal sera. Sera were obtained from pre-inoculated neonates demonstrating resistance to symptomatic infection upon subsequent intradermal inoculation.

I Sera were obtained from infected adult rabbits immune to symptomatic reinfection upon challenge (IRS) in resistant groups and from noninfected, VDRL nonreactive, nonimmune rabbits (NRS) in susceptible groups.

** Typical lesions with delays in incubation period compared to susceptible controls.

Table 3. The influence of nesting upon lesion development in neonatal rabbits $4 \frac{1}{2}$ to $6 \frac{1}{2}$ weeks of age*

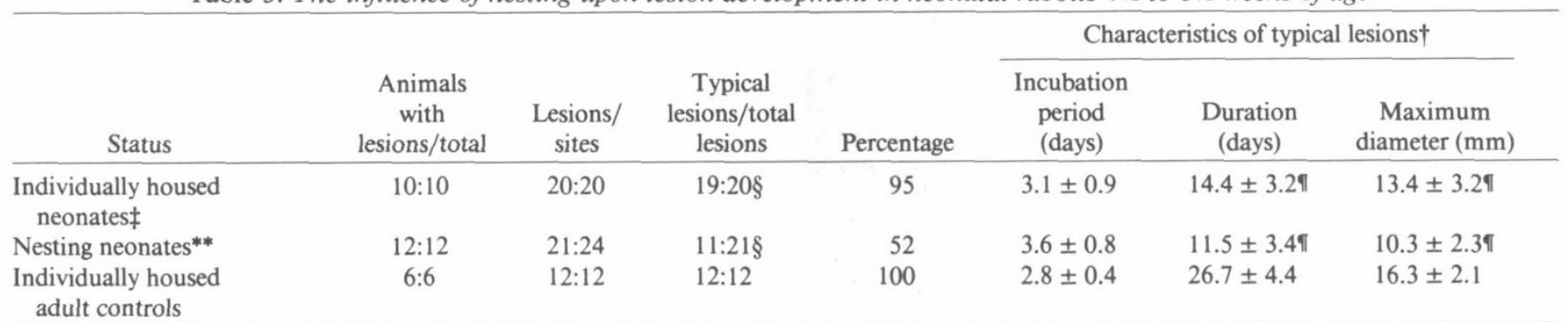

${ }^{*}$ Summary of three experiments. Neonates 31-46 days of age were inoculated intradermally at two sites with $1 \times 10^{6} \mathrm{~T}$. pallidum/site. Values are mean \pm SD.

$\dagger$ Erythematous, indurated, enlarged lesions that progress to ulceration.

$\ddagger$ Weaned at time of inoculation.

$\S 1: 20$ lesions of individually housed neonates were atypical; 10:21 lesions of nesting neonates were atypical.

If $p<0.01$, Student's $t$ test; comparison with adult controls.

** Weaned 6 to 20 days postinoculation. 
Table 5. Absence of serum neutralizing activity among 5-weekold noninfected neonates*

\begin{tabular}{lcc}
\hline & \multicolumn{2}{c}{ Serum neutralization } \\
\cline { 2 - 3 } & $\begin{array}{c}\text { No. of lesions/ } \\
\text { inoc. sites‡ }\end{array}$ & $\begin{array}{c}\text { Incubation period } \\
\text { (days) }\end{array}$ \\
\hline Serum samples $\dagger$ & $1: 20$ & 29.0 \\
$\begin{array}{c}\text { 1-week neonate } \\
\text { basal (4) }\end{array}$ & $18: 20$ & $14.4 \pm 2.6 \S$ \\
$\begin{array}{c}\text { 5-week neonate } \\
\text { basal (4) }\end{array}$ & $0: 10$ & \\
$\begin{array}{l}\text { IRS (2) } \\
\text { NRS (2) }\end{array}$ & $9: 10$ & $14.7 \pm 2.7$ \\
\hline
\end{tabular}

* Micro-NZ assay. See "Materials and Methods"; unheated sera; heated serum sample results satisfactory. Values are mean \pm SD.

$\dagger$ Matching neonate samples; 1 week $=6$ days and 5 weeks $=34$ days; number of samples in parentheses. IRS obtained from infected adult rabbits immune to symptomatic reinfection upon challenge with $T$. pallidum. NRS obtained from noninfected VDRL nonreactive adult rabbits susceptible to symptomatic infection with $T$. pallidum.

$\ddagger$ Five sites inoculated/test serum suspension.

$\S$ No significant differences, Student's $t$ test.

The requirement of a heat-labile component(s) was investigated by heating $\left(56^{\circ} \mathrm{C}, 30 \mathrm{~min}\right)$ neonate sera prior to testing. In contrast to adult IRS whose neutralizing ability was largely abrogated by heat inactivation, neonate sera continued to demonstrate neutralizing activity. It is apparent that the neutralizing ability of neonate sera was not dependent upon a heat-labile factor(s).

Absence of neutralizing activity in sera of noninfected 5-weekold neonates and breeding does. Evidence of waning resistance among neonatal rabbits at approximately 5 weeks of age prompted the initiation of studies to determine whether serum neutralizing activity similarly waned at this time period. Four neonates were bled at 1 week ( 6 days) and again at 5 weeks ( 34 days) of age for matching serum samples. As shown in Table 5, 1-week serum samples demonstrated essentially complete neutralization with the exception of the significantly delayed development of a single lesion at one of five neutralization inoculation sites in the serum sample from one neonate. In contrast, the matching 5-week sera showed little evidence of $T$. pallidum neutralization. These data provide convincing evidence that the neutralizing activity present in 1-week-old neonates had disappeared from the same animals by 5 weeks of age, a time at which resistance has been shown to diminish in some neonates. However, subsequent inoculation of these same 5-week-old neonates resulted in the development of atypical lesions among two of the animals while the remaining two rabbits remained free of lesions. Therefore, it seems apparent that while serum neutralizing activity may play a role in the innate resistance of neonates to $T$. pallidum infection, other factors may also be involved.

In an effort to determine whether the neutralizing activity of neonate sera was acquired in utero, serum samples from does were tested for their ability to neutralize $T$. pallidum. Two noninfected, VDRL nonreactive female rabbits were bled prior to mating, at 20 days gestation, at term and at 3 months postkindling. Additionally, two pools of neonate sera were prepared from three offspring ( 5 to 7 days old) of each doe. Neutralization of $T$. pallidum was not demonstrable by any of the doe sera. In contrast, the pooled offspring sera showed neutralizing activity. These data provided evidence that the ability of the neonate sera to neutralize $T$. pallidum was not acquired from the serum of their doe prior to birth.

\section{DISCUSSION}

In contrast to the inconclusive data provided by early investigators $(26,27,33)$, this report presents the first definitive evidence that neonatal rabbits are resistant to the development of dermal lesions upon intradermal inoculation with $T$. pallidum. In a single study by Pautrizel et al. (33), eight neonatal rabbits were inoculated with $1 \times 10^{7} \mathrm{~T}$. pallidum at 2,24 , or $48 \mathrm{~h}$ after birth; four developed asymptomatic infection while four either developed "characteristic" dark field positive lesions or gave no indication of infection as determined by lymph node transfers and serological tests. The route of inoculation, the length of observation, and a description of "characteristic" lesions were not provided. In the same study, these investigators failed to demonstrate transmission in utero. These findings led them to the conclusion that the fetus was innately resistant to infection with T. pallidum, and that this resistance was rapidly lost after birth. The absence of similarly infected adult control animals precludes any conclusions regarding the comparative degree of resistance among the inoculated newborns on the basis of their observed pattern of lesion development. Similarly, Kemp and Fitzgerald (26) failed to note transplacental transmission of $T$. pallidum to the rabbit fetus. Further, they observed that 12 of 36 animals inoculated intradermally or intratesticularly with $3 \times 10^{5} T$. pallidum at ages 81 and 103 days failed to develop lesions at the inoculated sites. Whether this represents evidence of resistance is unclear, inasmuch as the data with respect to the response of adult control rabbits infected with the same inoculum were not presented. In a previous study (27), they inoculated six rabbits intradermally at the base of the ear, at 10 weeks of age, with $3 \times$ $10^{6} \mathrm{~T}$. pallidum; none developed a lesion and only one was found to be infected upon lymph node transfer. Again, similarly inoculated adult controls were absent. The pattern of lesion development among the neonatal rabbits as described in our study contrasts sharply with the pattern demonstrated by similarly inoculated adult control animals. Lesions which occurred among 5- to 8-day-old neonates had significantly longer incubation periods and shorter durations, attained much smaller diameters, and were nonprogressive as compared to adult control lesions. Of greater significance was the absence of lesions at $55 \%$ of the inoculated sites, as compared to adult controls, in which $100 \%$ of the inoculated sites developed typical, progressive lesions. According to Turner and Hollander (52), a clinically recognizable lesion occurs in normal adult rabbits when the number of $T$. pallidum approaches $1 \times 10^{7}$ and the concentration of virulent treponemes can be determined by the number of days preceding its appearance. The rate of in vivo multiplication of $T$. pallidum has been determined to be 30 to $33 \mathrm{~h}$ with an approximate 10 fold increase in organisms every 4 days $(14,30)$. In this laboratory, a standard inoculum of $1 \times 10^{6} T$. pallidum has an incubation period of approximately 3 days with a range of 2 to 6 days. In the present study, adult control animals inoculated in this manner developed typical lesions within the appropriate incubation range and thus confirmed the virulence of the suspensions used in these experiments. Further, these data support the rate of multiplication in vivo as described. The absence or delayed incubation periods of neonate lesions may indicate a slower multiplication rate and/or decreased survival rate. In either event the number of inoculated organisms was kept below the threshold necessary for the appearance and progression of typical lesions. We have shown that neonates respond to intradermal inoculation with $T$. pallidum with a cellular infiltrate similar to adult control animals (17). Therefore poor lesion development cannot be attributed to the lack of an inflammatory response. Thus, the well controlled nature of our study leaves little doubt that neonates are resistant to symptomatic $T$. pallidum infection. It is also apparent that, as the age at which the neonates are inoculated increases, the characteristics of lesions which develop begin to approach those of adult controls. This was most evident with the development of typical lesions. Though not achieving the size of lesions observed among control animals, the appearance of progressive lesions in neonates clearly marks an age at which resistance has waned.

Inasmuch as neonates have had no previous exposure to $T$. pallidum, the mechanism(s) of resistance differs from that of adult rabbits with acquired immunity. It has been suggested that 
the resistance was due in part to an elevation in temperature caused by the huddling of neonates in the nest. The influence of temperature on the development of cutaneous lesions upon inoculation with $T$. pallidum has been well described $(25,51$, 52). Hollander and Turner (25) found that after intravenous inoculation, lesions occurred on the cooler, clipped areas of the back, whereas the warmer, unclipped areas remained free of lesions. In addition, rabbits which were inoculated intradermally and kept at cool temperatures $\left(18-20^{\circ} \mathrm{C}\right)$ developed lesions, whereas animals kept at warmer temperatures $\left(29-31^{\circ} \mathrm{C}\right)$ either remained free of lesions or developed lesions at fewer sites after delayed incubation periods. Generalized lesions after skin or testicular inoculations are known to localize preferentially on the cooler extremities of the body such as the feet, nose, and tail (10, 17). Optimum temperatures for in vivo survival and multiplication of $T$. pallidum have been determined to range from 35 to $37^{\circ} \mathrm{C}(25)$. In our study, the skin temperature of huddling neonates could not be determined accurately, but it is conceivable that it was raised above the optimum necessary for the development of typical progressive lesions. The design of experiments to address the problem was complicated by the fact that neonates could not be successfully separated from their respective does earlier than $4 \frac{1}{2}$ weeks of age. While nesting may exert some influence upon the appearance of typical lesions among neonates 31 to 46 days of age, the data are not conclusive. The implication of factors other than nesting was inferred by the observation that both groups differ significantly in the duration and maximum diameters of their typical lesions compared to adult control lesions. If, in fact, nesting was the primary influencing factor of resistance, it would be expected that typical lesions of the individually housed neonates would have parameters identical to those of controls and nesting neonates would be completely devoid of typical lesions.

A second potential influence upon the neonatal resistance observed in this study would seem to be nursing, which in some animals acts as a vehicle for the transmission of resistance $(6,8$, 59 ); colostrum and milk of several mammals are known to possess factors which may influence resistance $(18,22,32,36$, $44,54)$. However, there has been no evidence to substantiate a role for similar factors outside the gastrointestinal tract of rabbits and this has led to the conclusion by several investigators that the systemic protective factors transmitted in utero to the rabbit fetus are not supplemented by nursing after birth $(7,9,28,29)$. Our observations support this conclusion. A neutralization assay on the colostrum from a single doe failed to demonstrate inactivation of $T$. pallidum despite the fact that serum from the single offspring demonstrated neutralizing activity.

A contributory role of a potential serum factor(s) to the resistance of neonates observed in this study stems partially from the finding that neutralizing activity in the sera of these animals correlates to some degree with the status of their resistance. Neutralizing activity of the sera from 1-week (6 days)-old neonates and its disappearance at 5 weeks ( 34 days) of age, correlates closely with the pattern of resistance and susceptibility at these respective ages. The determination of the neutralizing activity in the sera of neonates between the ages of 1 and 5 weeks would provide more definitive information as to this relationship; these studies have been planned. It should again be stressed that our data only suggest a contributory role for serum factor(s) in neonatal resistance. Indeed, the absence or atypical appearance of lesions among two of four challenged 5-week-old neonates whose sera lacked detectable neutralizing activity indicates other influencing factors.

The association of "natural" antibody with innate resistance makes it a likely candidate as a resistance factor possibly responsible for neonate serum neutralizing activity. However, several facts preclude support for this mechanism. First, it has been determined that 4- to 5-week-old rabbits are deficient in "natural" antibody of their own origin $(29,44)$. Further, though other natural antibody classes have been identified (48), it is the IgM class which has been generally associated with natural antibody (47), and is known to be transmitted in utero in the rabbit (7, 23). Thus, the sera of does would also be expected to have neutralizing activity; however, sera obtained during gestation and within $38 \mathrm{~h}$ postkindling in this study failed to neutralize $T$. pallidum. In addition, serum neutralizing activity of neonatal rabbits was complement independent, a parameter not identified with natural bactericidal antibody activity (37). It is conceivable that the neutralizing factor(s) may be identical to the complement independent, heat-stable factors of $\beta$-lysin (41), rabbit platelet components $(1,24,57)$, or leukin (45), known to exert toxic effects upon Gram-positive organisms.

The role of lysozyme, per se, in the inactivation of $T$. pallidum is unknown; therefore, its association with resistance and neutralizing activity of neonate serum cannot be excluded. The presence of lysozyme in adult rabbits has been demonstrated (35); however, the relative levels of adult versus neonate lysozyme has not been determined. Therefore, it is conceivable that neonate sera contain elevated levels capable of inactivating T. pallidum.

Another hypothesis which may explain resistance and/or the neutralization of $T$. pallidum by neonatal serum is the absence of a nutritional factor(s) necessary for optimum survival and multiplication of the treponeme. It has been well documented, for example, that iron levels of a host can greatly influence the virulence of some organisms $(3,13,55,56)$. The inability to cultivate the organism in pure culture makes the direct investigation of nutritional requirements difficult, at best.

Thus, while several hypotheses can be advanced to explain the natural resistance of neonates to syphilitic infection, the definitive mechanism(s) has not been elucidated. Further, the increased susceptibility of rabbits with age remains an enigma. Perhaps the concentration of a resistance factor(s) is greater in neonates than in does and maturation brings about its natural reduction or elimination. Then again, in the event resistance is due to the absence of a nutritional factor, maturation may bring about its acquisition.

It is evident that our data are in direct contrast to those of Festenstein et al. $(15,16)$ who reported a runting syndrome among neonates inoculated through 2 weeks of age with eventual death by 8 weeks later. The failure to present data relative to the inoculum size and the occurrence of dermal lesions precluded further comparison. It is important to note that preliminary studies performed in this laboratory on neonates inoculated within $24 \mathrm{~h}$ of birth resulted in severely ill animals with a poor survival rate; the pattern of lesion development, however, was similar to that described in animals inoculated at 5 to 8 days of age.

As indicated earlier, numerous attempts have been made to infect the rabbit fetus $(4,16,19,26,27,33,40,53)$ and have led some investigators to the conclusion that fetal rabbits are innately resistant to $T$. pallidum infection $(16,26,33)$. Further, it has been concluded that a rapid loss of this fetal resistance occurs at birth based upon the appearance of "typical" lesions among some but not all neonates following inoculation at various ages $(26,33)$. Notwithstanding the earlier criticism of these studies based upon the absence of appropriate adult controls, failure to detect lesions among a proportionate number of their animals signifies a degree of resistance among their neonates. It has been demonstrated in this report that neonatal rabbits 1 week ( 5 to 8 days) through approximately 5 weeks of age maintain a degree of resistance to symptomatic infection with $T$. pallidum. However, the absence of typical dermal lesions does not preclude asymptomatic infection (17). The failure to determine the presence of asymptomatic infection in those studies designed to elucidate congenital transmission of the experimental infection may explain the negative results reported by many investigators $(4,16,26,27,33,40)$. Thus, the development of an experimental congenital syphilis model in which asymptomatic infection occurs may have merit in attempting to elucidate those factors 
responsible for the asymptomatic infection frequently observed in human neonates (48). Studies of resistance factors in an attempt to understand the complex interrelationship between $T$. pallidum and the unborn and the newborn host are warranted.

Acknowledgments. The authors wish to acknowledge valuable technical assistance provided by Drs. Sheila A. Lukehart, Nancy H. Bishop, Philip A. Hanff, and Mr. Robert Doe, assistance with statistical analysis by Dr. Diana Avila and typing of the manuscript by Geneva R. Moore.

\section{REFERENCES}

1. Amano T, Kato K, Shimizu R 1952 Studies on the role of plakin. Med J Asaka Univ 3:293

2. Annual Summary, Reported Morbidity and Mortality in the United States 1980 Publication CDC 81-8241. United States Public Health Service, Washington, DC

3. Barry DMJ, Reeve AW 1977 Increased incidence of Gram-negative neonatal sepsis with intramuscular iron administration. Pediatrics 60:908

4. Bessman A, Van Canneyt J 1932 Heredo-syphilis chez les lapereaus issus de parents atteints de manifestations oculaires specifiques. Soc Biol CR Hebdom 110:116

5. Bishop NH, Miller JN 1976 Humoral immunity in experimental syphilis. II. The relationship of neutralizing factors in immune serum to acquired resistance. J Immunol 177:197

6. Brambell FWR 1970 Transmission of immunity in the pig and horse. In: Neuberger A, Tatum EL (eds) Transmission of Passive Immunity from Mother to Young, Frontiers of Biology, vol 18. North-Holland Publishing Co, Amsterdam, pp 166-200

7. Brambell FWR 1970 Transmission of immunity in the rabbit. In: Neuberger A, Tatum EL (eds) Transmission of Passive Immunity from Mother to Young, Frontiers of Biology, vol 18. North-Holland Publishing Co, Amsterdam, pp 42-79

8. Brambell FWR 1970 Transmission of immunity in the ruminants. In: Neuberger A, Tatum EL (eds) Transmission of Passive Immunity from Mother to Young, Frontiers of Biology, vol 18. North-Holland Publishing Co, Amsterdam, pp 201-233

9. Brambell FWR, Hemmings WA, Henderson M, Oakley CL, Rowlands WT 1951 The accumulation of antibodies in the stomach contents of foetal rabbits. Proc R Soc Lond B 138:195

10. Brown WH, Pearce L 1920 Experimental syphilis in the rabbit. IV. Cutaneous syphilis. 2. Clinical aspects of cutaneous syphilis. J Exp Med 32:473

11. Brown WJ, Moore MB 1963 Congenital syphilis in the United States. Clin Pediatr 2:220

12. Budell JW 1976 Treatment of congenital syphilis. J Am Vener Dis Assoc 3:168

13. Bullen JJ, Rogers HJ, Griffiths E 1974 Bacterial iron metabolism in infection and immunity. In: Nielands JB (ed) Microbial Iron Metabolism. A Comprehensive Treatise. Academic Press, New York, pp 517-551

14. Cumberland MC, Turner TB 1949 The rate of multiplication of Treponema pallidum in normal and immune rabbits. Am J Syph 33:20

15. Festenstein H, Abrahams C, Bokkenheuser V 1967 Runting syndrome in neonatal rabbits infected with Treponema pallidum. Clin Exp Immunol $2: 311$

16. Festenstein $\mathrm{H}$, Bokkenheuser V 1961 Attempting induction of immunological tolerance in rabbits using living Treponema pallidum. $\mathrm{Br} \mathrm{J}$ Exp Pathol 42:158

17. Gamboa D, Miller JN, Lukehart SA, Baker-Zander SA, Sell S 1984 Experimental neonatal syphilis. II. Immunological responses of neonatal rabbits to intradermal inoculation with Treponema pallidum (Nichols strain). Pediatr Res 18:972

18. Goldman AS, Smith CW 1973 Host resistance factors in human milk. J Pediatr 82:1082

19. Grigoriew P 1929 Angeborene durch ein in die vordere augenkammer infiziertes kaninchen ubertragene syphilis. Dermatol Wochenschr 89:1122

20. Grossman J III 1976 Congenital syphilis. Teratology 16:317

21. Harter CA, Benirschke K 1976 Fetal syphilis in the first trimester. Am J Obstet Gynecol 7:705

22. Head JR, Beer AR 1979 "In vivo" and "in vitro" assessment of the immunologic role of leukocyte cells in milk. In: Ogra PL, Dayton D (eds) Immunology of Breast Milk. Raven Press, New York, pp 207-226

23. Hemmings WA, Jones RE 1962 The occurrence of macroglobulin antibody in maternal and foetal sera of rabbits as determined by gradient centrifugation. Proc R Soc Lond B 157:27

24. Hirsch JG 1960 Comparative bactericidal activities of blood serum and plasma serum. J Exp Med 112:15

25. Hollander DH, Turner TB 1954 The role of temperature in experimental treponemal infection. Am J Syph 38:489

26. Kemp JE, Fitzgerald EM 1938 Studies in experimental syphilis and the transference of immunity from immune syphilitic female rabbits to their offspring. J Invest Dermatol 1:353
27. Kemp JE, Rosahn PD 1937 Experimental study of congenital syphilis, including a study of the infectiousness of blood, uterus and placenta of pregnant rabbits with early syphilis. Bull Johns Hopkins Hosp 60:45

28. Kraehenbuhl JP, Campiche MA 1969 Early stages of intestinal absorption of specific antibodies in the newborn. An ultrastructural, cytochemical and immunological study in the pig, rat and rabbit. J Cell Biol 42:345

29. Landy M, Weidanz WP 1964 Changes in antibody levels during development of newborn rabbits. In: Landy M, Braun W (eds) Bacterial Endotoxin. Institute of Microbiology, Rutgers University, New Brunswick NJ, pp 279281

30. Magnuson HJ, Eagle H, Fleischman R 1948 The minimal infectious inoculum of Spirochaeta pallida (Nichols strain), and a consideration of its rate of multiplication in vivo. Am J Syph 32:1

31. Miller JN, Falcone VH, Golden B, Israel CW, Kuhn USG, Smibert RM 1971 Preparation of known or suspected infectious materials for animal inoculation. In: Miller JN (ed) Spirochetes in Body Fluids and Tissues, Manual of Investigative Methods. Charles C Thomas, Springfield, IL, p 22

32. Nagy LK, Mackenzie T, Bharucha Z 1976 "In vitro" studies on the antimicrobial effects of colostrum and milk from vaccinated and unvaccinated pigs on Escherichia coli. Res Vet Sci 21:32

33. Pautrizel R, Mayer G, Rivasseau A, Szersnovicz F 1957 Immunite naturelle du doetus de lapin vis-a-vis de Treponema pallidum. Immunol Rev 21:382

34. Peterson JC 1973 Congenital syphilis: a review of its present status and significance in pediatrics. South Med J 66:257

35. Prieur DJ, Olson HM, Young DM 1974 Lysozyme deficiency-an inherited disorder of rabbits. Am J Pathol 77:283

36. Reiter B, Oram JD 1967 Bacterial inhibitors in milk and other biological fluids. Nature 216:328

37. Roantree RJ, Rantz LA 1960 A study of the relationship of the normal bactericidal activity of human serum to bacterial infection. J Clin Invest 39:72

38. Robinson RCV 1969 Congenital syphilis. Arch Dermatol 99:599

39. Saxoni F, Lapatsanis P, Pantelakis SN 1967 Congenital syphilis: a description of 18 cases and re-examination of an old but ever present disease. Clin Pediatr 6:687

40. Seiffert W 1934 Experimentelle untersuchungenuber die infection mit Spir pallida dürch kohabitation und dürch die plazenta. Zeitschr Immun Exp Ther 83:386

41. Schultz LD, Wilder MS 1973 Fate of Listeria monocytogenes in normal rabbit serum. Infect Immun 7:289

42. Silverstein AM 1962 Congenital syphilis and the timing of immunogenesis in the human foetus. Nature 194:196

43. Silverstein AM, Lukes RJ 1962 Fetal response to antigenic stimulus. I. Plasmacellular and lymphoid reactions in the human fetus to intrauterine infection. Lab Invest 11:918

44. Skarnes RC 1978 Humoral bactericidal systems: antibacterial potential of serum from young animals. Infect Immun 19:510

45. Skarnes RC, Watson DW 1956 Characterization of leukin: an antibacterial factor from leukocytes active against Gram-positive pathogens. J Exp Med 104:829

46. Sokal AB, Aroujo TR 1973 Congenital syphilis, a new (old) diagnostic problem. J Indiana State Med Assoc 66:23

47. Solomon JB 1971 Foetal and neonatal immunology. In: Neuberger A, Tatum EL (eds) Frontiers of Biology, vol 20. American Elsevier Publishing Co, New York, p 150

48. Syphilis, a Synopsis 1968 Publication 1660. United States Public Health Service, Washington, DC, pp 86-95

49. Tan KL 1973 The re-emergence of early congenital syphilis. Acta Paediatr Scand 62:601

50. Teberg A, Hodgman JE 1973 Congenital syphilis in newborn. Calif Med 118:5

51. Turner TB, Hollander DH 1957 Factors affecting the evolution of experimental treponematosis. In: Biology of the Treponematoses. World Health Organization, Geneva, pp 73-82

52. Turner TB, Hollander DH 1957 The experimental disease in laboratory animals. In: Biology of the Treponematoses. World Health Organization, Geneva, pp 31-49

53. Uhlenhuth P, Mulzer P 1913 Beitrage zur experimentellen Pathologic und Therapie der Syphilis mit besonder Berücksichigung der Impf.-Syphilis der Kaninchen. Arbeit Kaiserl Gesund 44:307

54. Waksman BH 1979 Summary of breast milk and maternal-neonatal interaction. In: Ogra PL, Dayton D (eds) Immunology of Breast Milk. Raven Press, New York, pp 257-272

55. Weinberg ED 1978 Iron and infection. Microbiol Rev 42:45

56. Weinberg ED 1971 Roles of iron in host-parasite interactions. J Infect Dis 124:401

57. Weksler BB, Nachman RL 1971 Rabbit platelet bactericidal protein. J Exp Med 134:1114

58. Wilson GS, Miles A (eds) 1975 Immunoglobulin IgM. In: Topley and Wilson's Principles of Bacteriology, Virology and Immunity. The Williams and Wilkins Company, Baltimore, pp 1367-1370

59. Wilson GS, Miles A (eds) 1975 Passive congenital immunity. In: Topley and Wilson's Principles of Bacteriology, Virology and Immunity. The Williams and Wilkins Company, Baltimore, pp 1421-1425

60. Woody NC, Sistrunk WF, Platou RV 1963 Congenital syphilis: a laid ghost walks. J Pediatr 64:63 